\title{
Robótica de Portas Abertas: disseminando o conhecimento da Robótica Educacional para escolas da rede pública da Paraíba
}

\author{
Jarles Tarsso Gomes Santos' $\mathbf{1}$, Jaian Tales Gomes Santos ${ }^{2}$, Verônica Araujo da \\ Costa $^{2}$
}

${ }^{1}$ Instituto Metrópole Digital (IMD) - Universidade Federal do Rio Grande do Norte (UFRN) - CEP: 59.078-970 - Natal - RN - Brasil

${ }^{2}$ Centro de Ciências Exatas e Sociais Aplicadas (CCEA) - Universidade Estadual da Paraíba (UEPB) - CEP: 58.706-560 - Patos - PB - Brasil

jarlestarsso@gmail.com, jaian tales@hotmail.com, veronicaaraujodacostågmail.com

\begin{abstract}
This paper reports the first experiences of the project entitled Robótica de Portas Abertas, which seeks to disseminate knowledge about Educational Robotics to schools that have pedagogical material as kits of specialized companies, but do not use. In this first part of the project, two schools received training. The kits were presented to teachers and students through practical activities that sought to engage teachers and students in the use of robotics as a pedagogical tool. The study allowed schools to know possibilities for integrating robotics into the school curriculum, using the available robotics kits at the school, contributing to the teaching can become more dynamic and motivating for the student.
\end{abstract}

Resumo. Este trabalho relata as primeiras experiências do projeto intitulado Robótica de Portas Abertas, que busca disseminar o conhecimento acerca da Robótica Educacional a instituições de ensino que possuem material pedagógico como kits de empresas especializadas, porém não fazem uso do mesmo. Nessa primeira fase do projeto, duas escolas receberam formação, com objetivo de apresentar os kits para professores e alunos, através de atividades práticas que buscaram engajar docentes e discentes no uso da robótica como ferramenta pedagógica. O estudo permitiu às escolas conhecer possibilidades para integrar a robótica ao currículo, usando o material pedagógico disponível na instituição, contribuindo para que o ensino possa se tornar mais dinâmico e motivador para o aluno.

\section{Introdução}

A robótica se caracteriza como uma tecnologia que possibilita desenvolver autômatos compostos por partes mecânicas programáveis, visando realizar determinadas funções, atendendo principalmente às indústrias. Esse ramo da mecânica tem crescido consideravelmente nos últimos anos e ajudado a expandir diversas áreas, como saúde, segurança, agricultura, entre outros, devido a velocidade com que objetos robóticos conseguem trabalhar, além de serem ferramentas que operam incessantemente.

Dentre diversas possibilidades, a robótica passa a permear também os meios educacionais. Atualmente, inúmeros estudos abordam o uso da robótica educacional (RE) 
VIII Congresso Brasileiro de Informática na Educação (CBIE 2019)

Anais do XXV Workshop de Informática na Escola (WIE 2019)

em disciplinas do currículo escolar, desafiando o estudante a criar soluções para determinados problemas, trabalhando seu raciocínio lógico por meio do desenvolvimento de atividade com partes mecânicas e softwares de programação, promovendo uma aprendizagem significativa e permitindo que o estudante construa seu conhecimento mediante a exploração do material estudado [Oliveira e Lins 2013].

De acordo com Santos e Lima (2018) a integração da robótica à educação básica pode ocorrer mediante o uso de kits fornecidos por empresas especializadas ou através do uso de sucata. O uso desses objetos permite aprender conceitos de programação, eletrônica, meio ambiente e desenvolver habilidades para o trabalho em equipe, desde que o professor explore bem essas capacidades [Santos e Lima 2018; Caitano e Azevêdo 2016].

A RE permite também sua integração num caráter interdisciplinar, em que o professor pode utilizar como benefício a robótica para conduzir uma atividade que envolva várias disciplinas, da Matemática à Língua Portuguesa [Santos et al. 2018]. Além disso, permite o desenvolvimento de competências para o século XXI, como resolução de problemas, pensamento crítico, criatividade, tomada de decisões, entre outras [Machado, Câmara e Willians 2018].

A RE está presente em diversas escolas ao redor do mundo. Como apontado por Quintanilha (2008) vários países já fazem uso constante dessa ferramenta no ensino, que é vista como prioridade em alguns deles. Ainda de acordo com o autor, na Holanda e Alemanha, por exemplo, a RE está presente em todas as escolas, sem exceção, enquanto outros como Inglaterra, Itália, Espanha, Canadá e Estados Unidos buscam o mesmo feito. $\mathrm{Na}$ América Latina, os números são de menor expressão, entretanto, estudos recentes mostram que países como Peru e México já adotam estratégias para o uso da RE em sala de aula.

No Brasil, a RE ainda está em crescimento, contando com vários projetos que visam incentivar o uso dessa ferramenta na educação [Andrade, Nunes e Lima 2016]. O Estado da Paraíba, por exemplo, tem investido consideravelmente em RE. Só no ano de 2013, o total investido foi de aproximadamente R \$22,5 milhões oriundos do Tesouro Estadual para a aquisição de laboratórios de robótica nas 150 escolas de Ensino Médio [Paraíba 2013]. Junto com os kits, o Estado ofereceu formação para que os professores pudessem aplicar a robótica na sua prática pedagógica.

Entretanto, mesmo com o investimento realizado, diversas escolas contempladas não utilizam o material, que tende a ficar obsoleto pelo desuso ou simplesmente anexado por anos em algum local da escola, sem que seu potencial seja explorado. Almeida e Valente (2011) apontam que o maior problema ao relacionar as tecnologias digitais de informação e comunicação (TDIC) na educação está na má condução das formações, que focam na técnica, sem que o docente compreenda como deve ocorrer a integração das TDIC ao currículo, fazendo com que ele não compreenda a maneira adequada para a inserção da tecnologia em sua prática pedagógica. Diante disso, os autores afirmam que o conhecimento pedagógico deve sempre acompanhar o conhecimento técnico, pois são dependentes entre si.

Diante dessas dificuldades, o presente estudo busca apresentar os primeiros passos do projeto intitulado Robótica de Portas Abertas, que visa incentivar o uso da RE nas escolas do Estado da Paraíba, mapeando, inicialmente, instituições contempladas com kits de robótica pelo Estado mas que não fazem uso como material pedagógico. Dessa 
VIII Congresso Brasileiro de Informática na Educação (CBIE 2019)

Anais do XXV Workshop de Informática na Escola (WIE 2019)

forma, buscou-se mostrar a professores e estudantes o potencial que a robótica possui como ferramenta pedagógica para o ensino, por meio de formações realizadas por professores e estudantes de uma instituição que possui a RE como um dos seus principais métodos de ensino.

\section{A Robótica Educacional no Estado da Paraíba}

Nos últimos anos, o interesse pela robótica por parte do Governo da Paraíba cresceu consideravelmente. Segundo reportagem encontrada no website oficial do Governo do Estado, o objetivo da ação é estimular o estudo de conceitos multidisciplinares, abrangendo conteúdos como Física, Química, Matemática e Geografia. A ideia principal é propor ao estudante o projeto e construção de um experimento investigativo e exploratório.

Além do grande investimento para equipar a maior parte das escolas estaduais, o Estado incentiva a participação das escolas na Olimpíada Brasileira de Robótica (OBR), que ocorre anualmente. Nela há a participação de todos os estudantes de qualquer escola pública ou privada do ensino fundamental, médio ou técnico em todo o território nacional, e é uma iniciativa pública, gratuita e sem fins lucrativos. A OBR tem por objetivo estimular jovens no ingresso de carreiras científico-tecnológicas, contribuir para identificar jovens talentosos e buscar promover debates para que o processo de ensinoaprendizagem brasileiro possa ser reorganizado [Paraíba 2016].

Outra iniciativa do Governo da Paraíba é a RoboTecPB, realizada em parceria com a Fischertechnik e Brink Mobil. Constitui-se em uma competição que envolve a montagem de kits tecnológicos de RE, na qual os estudantes têm por objetivo fazer uso da criatividade e aplicá-la à robótica [Paraíba 2016]. A RoboTecPB visa estimular o interesse de estudantes e professores acerca da ciência, tecnologia e inovação e incitar o espírito de equipe.

\subsection{Kits da Fischertechnik}

Todas as escolas da Paraíba contempladas com um laboratório de robótica, recebem diversos kits da empresa alemã Fischertechnik (Figura 1). Além das peças para montagem dos robôs, os kits possuem manuais de orientação para montagem e uso como ferramenta pedagógica.

A empresa dispõe de uma gama de kits para comercialização, que são exportados para todo o mundo. Seus kits, na grande maioria, são compostos de peças que podem ser encaixadas para dar forma a um robô, auxiliado de motores e sensores. Todas as peças são conectadas ao controlador principal, chamado TXT Controller, que serve para controlar os atuadores e as informações dos sensores.

A programação dos kits ocorre por meio da linguagem $R O B O$ pro, que funciona baseada na linguagem Logo, através de um sistema de arrastar e soltar. A Fischertechnik possui uma filosofia de sustentabilidade, com seu material produzido num bioplástico ecologicamente eficiente [Fischer Brasil 2019]. 
VIII Congresso Brasileiro de Informática na Educação (CBIE 2019)

Anais do XXV Workshop de Informática na Escola (WIE 2019)

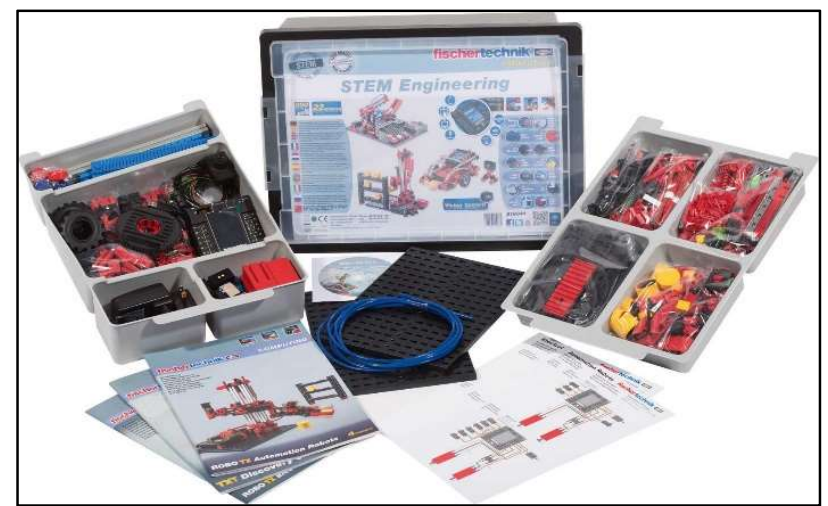

Figura 1. Exemplo de Kit da empresa Fischertechnik.

\section{Material e Métodos}

A proposta do projeto Robótica de Portas Abertas surgiu durante formações realizadas para professores dos Cursos Técnicos do Estado da Paraíba. Após um debate acerca da importância da robótica como ferramenta pedagógica, alguns professores afirmaram que suas escolas possuíam kits para uso da robótica em sala, porém jamais foram utilizados. Diante disso, a escola responsável por este estudo buscou formas para minimizar a quantidade de instituições em que esse fato ocorria.

Foi sugerido, portanto, oficinas que levassem propostas para uso da RE em algumas escolas, mostrando aos estudantes os trabalhos já desenvolvidos na escola responsável pelo projeto, bem como apresentando a professores de outras instituições de ensino, métodos de inserção em sala de aula.

A primeira etapa do projeto realizou a formação para duas instituições de ensino do Estado, que receberam um total de 20 kits da empresa Fischertechnik. As formações ocorreram por meio de demonstrações práticas acerca do uso da robótica como ferramenta pedagógica, apresentando possíveis projetos que podem ser desenvolvidos utilizando os kits fornecidos às escolas. Durante os momentos formativos, professores puderam observar formas para abordar conceitos presentes em várias disciplinas, que podem ser lecionados tendo como ferramenta metodológica os kits de robótica.

Para o andamento das oficinas, foram utilizados além dos kits de robótica da Fischertechnik, smartphones para controlar alguns robôs projetados e blocos que foram utilizados para simular obstáculos em atividades propostas. Como formadores, participaram três professores da instituição que realizou o projeto, além de oito estudantes que fazem parte do projeto Robótica de Portas Abertas. Os estudantes fazem parte do Curso Técnico em Informática oferecido pela mesma.

Para este estudo, as escolas que receberam as formações foram classificadas como Instituição A e Instituição B. A Instituição A possui a modalidade de ensino médio integrado a educação profissional, com os Cursos Técnicos em Administração e Informática. Um dos motivos que a escola afirma para a falta de uso dos equipamentos, é a inexistência de espaço adequado para alocá-los. Já a Instituição B, atende a modalidade de ensino fundamental II e recebeu os kits recentemente. Os professores dessa instituição receberam a formação, porém até o momento deste estudo os kits não haviam sido utilizados.

As formações com as escolas ocorrem em dois momentos distintos. Para a 
VIII Congresso Brasileiro de Informática na Educação (CBIE 2019)

Anais do XXV Workshop de Informática na Escola (WIE 2019)

Instituição A, a formação ocorreu no laboratório de robótica da escola que desenvolve este projeto, onde os próprios estudantes demonstraram como era utilizada a robótica dentro da escola. A formação contou com cerca de cinquenta estudantes da Instituição A, mais cinco professores.

Para a Instituição B, foi necessário a ida até a escola a receber a formação. Os kits foram apresentados a todas as turmas da escola, que dispõe de um total de 315 estudantes, divididos em 14 turmas. Todos os professores que se encontravam em aula durante o momento da formação, puderam participar das atividades, observando as possibilidades apresentadas.

\section{Resultados e Discussão}

De acordo com Vargas et al. (2012) a inserção da robótica na educação proporciona uma aprendizagem lúdica e motivadora, fazendo com que o estudante veja na prática os conceitos abordados em sala. Essa inserção, porém, depende enormemente da apropriação do professor para seu uso, de modo que ele saiba definir as potencialidades que uma TDIC possui para o estudo de determinado conteúdo, fazendo com que sua exploração contribua para a construção do conhecimento do estudante [Almeida e Valente 2011].

A robótica, nesse contexto, permite que o professor desenvolva sequências didáticas, podendo adequá-las a diferentes perspectivas, que dependem da intenção do docente no que diz respeito ao feedback do estudante [Santos et al. 2018], ou seja, a definição do conteúdo que se espera que o estudante aprenda com a aplicação da sequência didática proposta.

As formações desenvolvidas junto as escolas, portanto, buscaram apresentar além de uma aprendizagem lúdica e motivadora, formas para que o professor consiga desenvolver sua prática com o auxílio da RE, mostrando as possibilidades para aplicação em algumas disciplinas do currículo.

\subsection{A formação da Instituição $A$}

Realizado no laboratório de robótica da escola responsável por este estudo, a formação da Instituição A teve como principal foco mostrar como ocorrem as competições de robótica pelo Brasil, ensinando-os possibilidades para iniciar projetos que os habilitem a participar. Além disso, permitiu que os professores observassem formas de aplicar a robótica em sala de aula, trabalhando conceitos relacionados a Matemática, Química e Física.

Para os professores, foram apresentados os materiais que acompanham os kits, como os softwares e os manuais que visam contribuir para guiá-los na condução de atividades utilizando como proposta metodológica a RE. Almeida e Valente (2011) apontam para a importância do conhecimento técnico por parte do professor, devendo estar em sincronia com o conhecimento do conteúdo. Os autores afirmam ainda que um dos motivos que leva o professor a não utilizar TDIC em sua prática, é a superioridade do estudante na apropriação das ferramentas digitais, fazendo com que haja um desconforto por parte do docente ao utilizá-las.

Durante o momento prático com os estudantes, foram apresentados os kits da Fischertechnik, onde os monitores mostraram como ocorre a montagem e programação 
VIII Congresso Brasileiro de Informática na Educação (CBIE 2019)

Anais do XXV Workshop de Informática na Escola (WIE 2019)

dos projetos (Figura 2). Para a oficina, foi utilizado o robo TXT Explorer, que consiste em um robô de exploração capaz de operar de forma autônoma, após desenvolvida sua programação. O robo TXT Explorer atua sobre uma plataforma projetada, que possui diversas linhas, simulando as ruas de uma cidade. O robô também pode se deparar com obstáculos à sua frente, devendo ser capaz de desviar e voltar a seguir a linha. É comumente usado nas competições de robótica, em que o robô deve realizar diversas ações de forma autônoma.

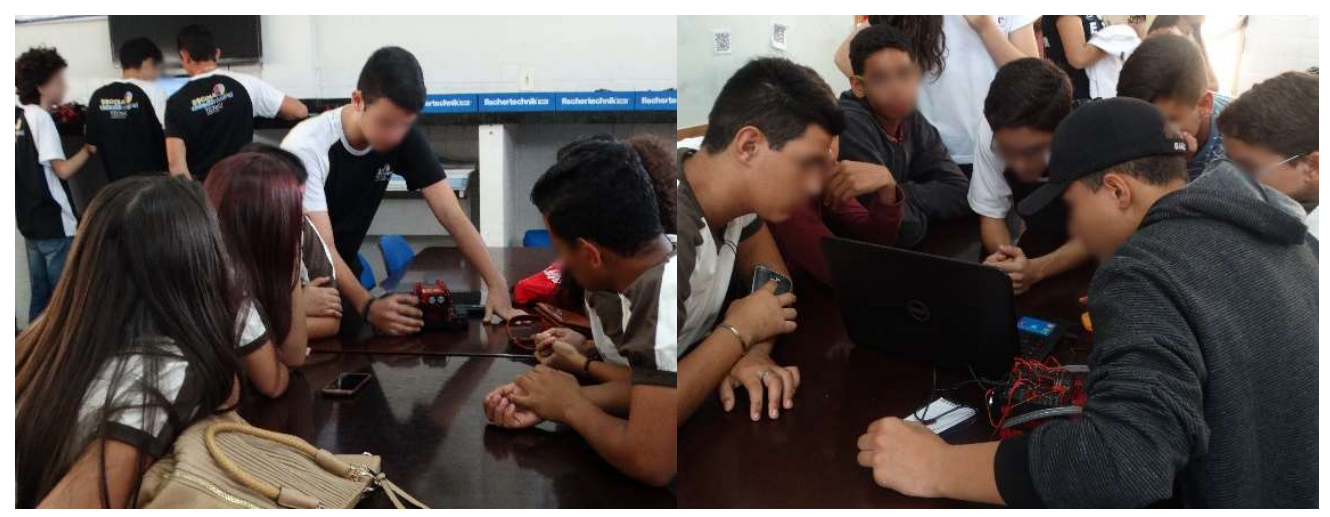

Figura 2. Monitores apresentando o robo TXT Explorer e sua programação.

Após a montagem e programação dos kits, os estudantes puderam verificar a programação e realizar ajustes (Figura 3), recebendo suporte dos monitores da oficina. Esse momento permitiu observar a motivação gerada por uma atividade desafiadora, em que a cada erro, o interesse dos estudantes aumentava para conseguir alcançar o objetivo. Chitolina, Noronha e Backes (2016) destacam que a proposta desafiadora é uma das características ofertadas pela RE, levando o estudante a pensar em soluções, usando seu raciocínio para formular estratégias e hipóteses, a fim de serem testadas e validadas. Os autores complementam que por meio da programação, o estudante pode materializar o seu pensamento.

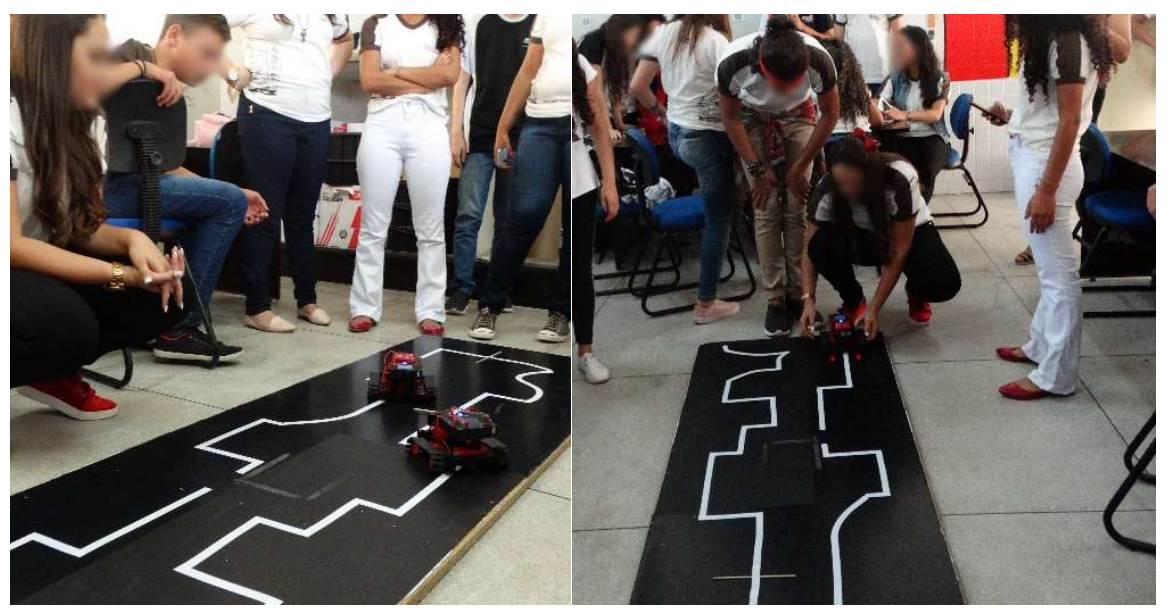

Figura 3. Participantes da formação testando a programação dos seus robôs.

Concluindo as atividades, a Instituição A foi orientada acerca das possibilidades para realizar a montagem do seu laboratório, até então mantido sem uso. Uma visita a escola foi agendada, buscando auxiliar na montagem, bem como realizar uma nova oficina para estudantes e professores que não tiveram a possibilidade de participar na 
VIII Congresso Brasileiro de Informática na Educação (CBIE 2019)

Anais do XXV Workshop de Informática na Escola (WIE 2019)

primeira oportunidade.

\subsection{A formação da Instituição B}

A visita a Instituição B ocorreu no prédio da escola a ser formada, contando com a participação de todas as turmas e os professores que se encontravam em aula durante as atividades. Os momentos formativos com cada turma duraram em torno de 20 minutos, onde foram apresentados os kits que a escola recebeu e alguns possíveis projetos (Figura 4) que podem ser desenvolvidos com auxílio do material que acompanha os kits.

Após a explanação acerca de como poderão ocorrer as atividades com auxílio da $\mathrm{RE}$, foram apresentados projetos como um sistema de alarme para uma porta, que assim que aberta, emite um sinal sonoro como alerta, que só encerra ao ser pressionado um botão. O projeto permite que professores mostrem o funcionamento de circuitos elétricos, bem como explorem os primeiros passos acerca da lógica de programação.

Outro projeto apresentado na atividade foi o protótipo de um guindaste, capaz de conduzir objetos de um local para outro. Nele, o professor pode explorar conceitos como o equilíbrio do guindaste na condução dos objetos, ao levantá-los ou baixá-los. É possível abordar as diferenças entre velocidade para levantar objetos com diferentes pesos e a força exigida para que o motor trabalhe levando em consideração diferentes massas. O kit conta com diversos acessórios que podem incrementar a atividade, como carrinhos para simular atividades em uma empresa, dando maior significado ao processo.

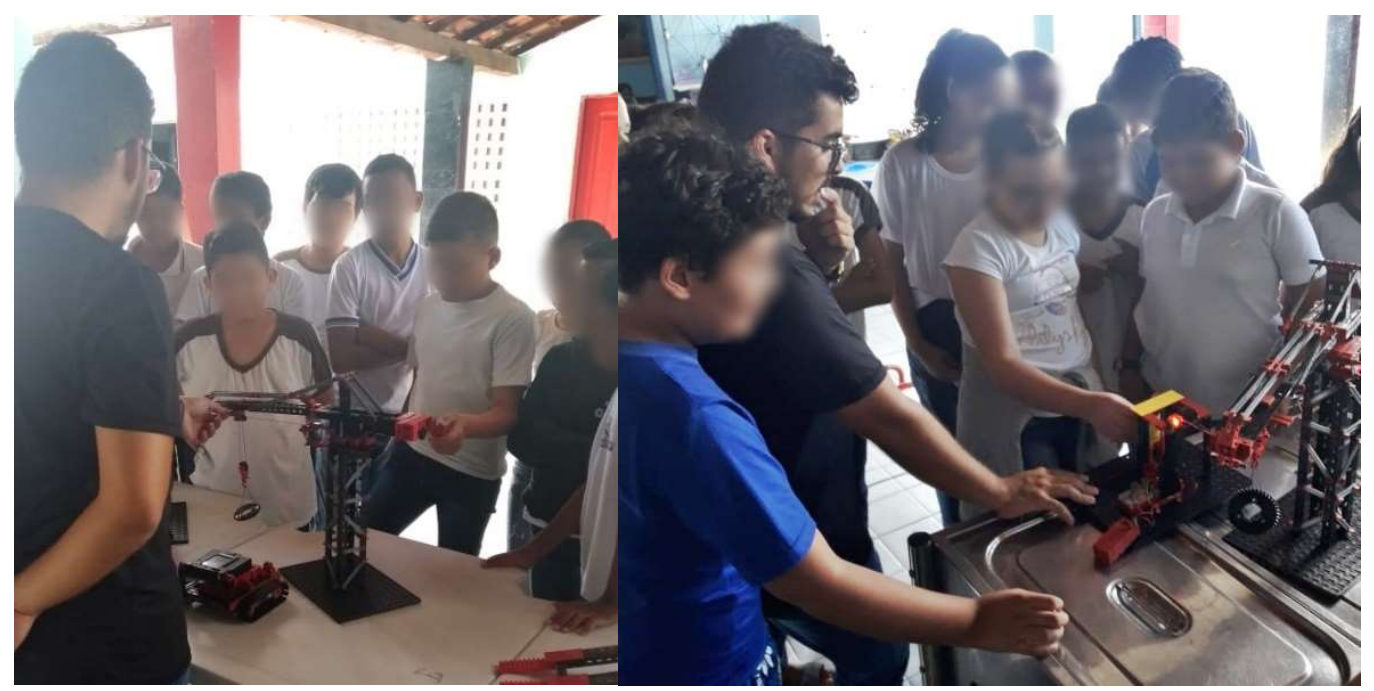

Figura 4. Apresentação de projetos desenvolvidos com os kits da escola.

Após a apresentação de alguns projetos, os estudantes puderam manipular um robô utilizando o software FtApp, que consiste em uma ferramenta capaz de controlar os motores dos kits de robótica da Fischertechnik através de um smartphone. Com a ferramenta, os estudantes podem guiar o robô para diferentes direções. Na oficina realizada, os estudantes tiveram a missão de guiar o robô até determinados objetos, que deveriam ser empurrados ao alvo marcado no chão (Figura 5).

Essa atividade permite que o professor apresente o conceito de ângulos, podendo utilizar diversos obstáculos ou simplesmente desenhando um percurso que deve ser observado pelo estudante, fazendo com que ele compreenda a necessidade de girar para diferentes direções e o quanto é necessário girar para que o robô continue no percurso. 
VIII Congresso Brasileiro de Informática na Educação (CBIE 2019)

Anais do XXV Workshop de Informática na Escola (WIE 2019)

De acordo com Meireles e Mafra (2016) a geometria é um conteúdo que pode ser explorado por meio da RE, buscando a compreensão acerca do conceito de ângulos e alguns outros cálculos simples. Para isso, o professor pode utilizar a linguagem padrão da interface do robô, fazendo com que o próprio estudante informe a direção exata em que o robô deve girar.

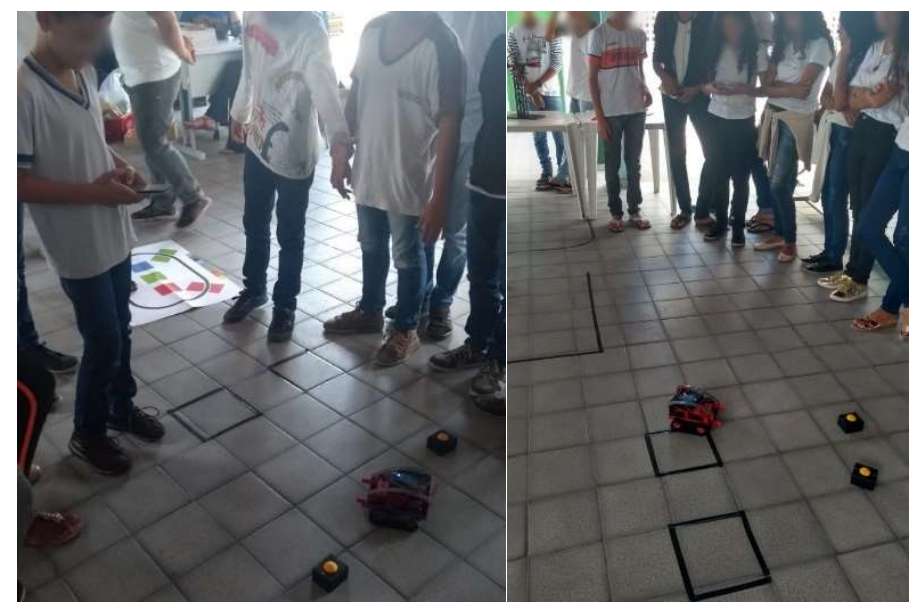

Figura 5. Estudantes manipulando os kits por meio do smartphone.

\section{Conclusão}

Durante a realização das oficinas, ficou evidente a ludicidade proporcionada pela robótica, configurando-se uma ferramenta que pode gerar grande motivação para o estudante durante a realização das atividades. Afinal, a robótica constitui-se uma ferramenta de teor prático, em que o estudante tem a possibilidade de construir seu conhecimento e verificar o seu pensamento por meio das ações do robô.

Percebe-se que os Estados realizam grandes investimentos para a aquisição de material pedagógico que possam auxiliar os professores em sala de aula. Entretanto, constatou-se que não há formações continuadas para o acompanhamento do uso da robótica nas escolas. Além disso, os professores possuem pouco tempo destinado ao planejamento de aulas, que acarreta na falta de estímulo para trabalhar com essas ferramentas com frequência.

Cabe aos Estados, portanto, o dever de oferecer além de formações, o acompanhamento frequente nas escolas, permitindo que haja o domínio dos materiais pelo docente. É importante também que haja uma mudança de postura do próprio professor, para que o conhecimento prévio do estudante possa servir como complemento para as atividades desenvolvidas em sala de aula.

Este estudo consegue alcançar seus objetivos iniciais, proporcionando um momento formativo que possa contribuir para que as escolas passem a utilizar a robótica com maior frequência em sala, mostrando experiências exitosas e dando novas possibilidades para que educadores façam uso dessa ferramenta com grande potencial pedagógico.

É importante frisar que as formações relatadas podem não ser suficientes para garantir a continuidade do uso da robótica nas escolas que participaram dos momentos, visto que apenas um momento formativo é insuficiente para apresentar todas as possibilidades que a robótica possui para melhorar o contexto de sala de aula. Faz-se 
VIII Congresso Brasileiro de Informática na Educação (CBIE 2019)

Anais do XXV Workshop de Informática na Escola (WIE 2019)

necessário que haja acompanhamento das atividades pedagógicas das escolas, visando auxiliar nas dificuldades que naturalmente podem surgir, evitando que esses empecilhos desmotivem professores e culminem no abandono desse recurso.

O Projeto Robótica de Portas Abertas encontra-se em estágio inicial, porém com pretensões de atuar em novas instituições de ensino que venham a receber os kits que o Estado da Paraíba fornece. Além disso, espera poder contribuir também com instituições que não possuam material adequado para a condução de aulas com a RE, fazendo uso dos kits já presentes na escola que desenvolve este estudo, bem como utilizando a robótica reciclável, com auxílio de sucata.

\section{Referências}

Almeida, M. E. B., Valente, J. A. (2011). Tecnologias e Currículo: trajetórias convergentes ou divergentes?. São Paulo: Paulus.

Andrade, F. O., Nunes, A. K. F., Lima, E. S. (2016). A contribuição da Robótica Educacional para o uso de Metodologias Ativas no Ensino Médio. In: $7^{\circ}$ Simpósio Internacional de Educação e Comunicação.

Caitano, A., Azevêdo, E. (2016). Oficina de Robótica Pedagógica Livre: um instrumento de multidisciplinaridade. In: Congresso Regional sobre Tecnologias na Educação (Ctrl $+\mathrm{e})$.

Chitolina, R. F., Noronha, F. P. T., Backes, L. (2016). A Robótica Educacional como tecnologia potencializadora da aprendizagem: das ciências da natureza às ciências da computação. Educação, Formação \& Tecnologias, 9(2).

Fischer Brasil (2019). Fischertechnik. Disponível em: <http://www.fischerbra sil.com.br/Home/Empresa/Empresas-do-Grupo/fischertechnik.aspx $>$.

Machado, A., Câmara, J., Willians, V. (2018). Robótica Educacional: Desenvolvendo Competências para o Século XXI. In: III Congresso sobre Tecnologias na Educação $(\mathrm{Ctrl}+\mathrm{E})$.

Meireles, J. C., Mafra, J. R. S. (2016). A robótica como técnica de aprimoramento no ensino da Matemática no Quilombo de Peafú - Monte Alegre/Pará. In: Encontro Nacional de Educação Matemática (ENEM).

Oliveira, E. S., Lins, A. F. (2013). Um breve prognóstico do uso da Robótica Educativa na prática educacional de professores discentes do Mestrado MECM-UEPB. In: VII Congreso Iberoamericano de Educación Matemática (CIBEM).

Paraíba (2013). Governo entrega Laboratórios de Robótica a 150 escolas estaduais. Disponível em: $<$ http://paraiba.pb.gov.br/governo-entrega-laboratorios-de-robotica-a150-escolas-estaduais/>.

Paraíba (2016). Olimpíada Brasileira de Robótica prorroga inscrições para a modalidade prática até o dia 20 de maio. Disponível em: <http://paraiba.pb.gov.br/olimpiadabrasileira-de-robotica-prorroga-inscricoes-para-amodalidade-pratica-ate-o-dia-20-demaio/>.

Paraíba (2016). Governo do Estado Realiza Primeira Competição Paraibana de Robótica. Governo da Paraíba. Disponível em: <http://paraiba.pb.gov.br/governo-doestadorealiza-primeira-competicao-paraibana-de-robotica/>. 
VIII Congresso Brasileiro de Informática na Educação (CBIE 2019)

Anais do XXV Workshop de Informática na Escola (WIE 2019)

Quintanilha, L. (2008). Irresistível robô. ARede, 3(34).

Santos, J. T. G., Lima, J. F. S. (2018). Robótica Educacional e Construcionismo como proposta metodológica para o desenvolvimento de ambientes de aprendizagem significativa. Novas Tecnologias na Educação, 16(2).

Santos, L. M., Basso, S. J. L., Freitas, L. K. M., Tieppo, T. A. M. (2018). Ensinando Programação e Robótica para o Ensino Fundamental. In: III Congresso sobre Tecnologias na Educação (Ctrl+E).

Vargas, M. N., Menezes, A. G. C., Massaro, C. M., Gonçalves, T. M. (2012). Utilização da Robótica Educacional como ferramenta lúdica de aprendizagem na Engenharia de Produção: introdução à produção automatizada. In: XL Congresso Brasileiro de Educação em Engenharia (COBENGE). 